\title{
Domestic unintentional injury of 1 to 5 -year-old children in a rural area of West Bengal, India: a community-based study
}

\author{
SITIKANTHA BANERJEE, BOBBY PAUL, KAJARI BANDYOPADHYAY and APARAJITA DASGUPTA \\ All India Institute of Hygiene and Public Health, Kolkata, India
}

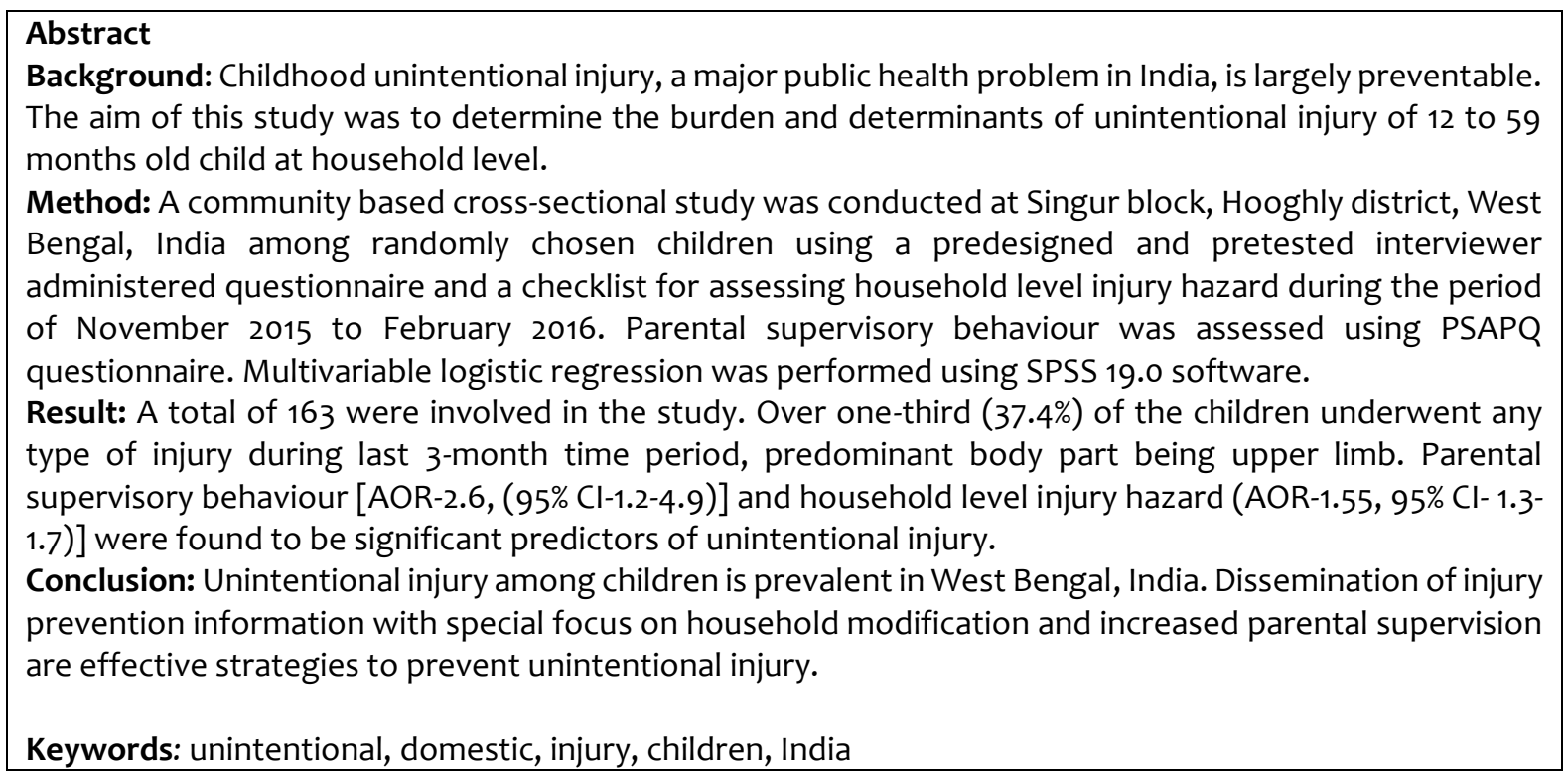

\section{Introduction}

Unintentional injuries are major causes of morbidity and mortality in children, resulting in over 630,000 deaths annually in children less than 15 years of age in 2011(WHO, 2016). Worldwide, South-East Asia (SEA) alone contributes to $31 \%$ of the burden of injury and $27 \%$ of injury related mortality (Chaturvedi et al., 2008). In India, injuries are the fourth leading cause of death in children under 15years age (WHO, 2008). National Crime Bureau and few independent studies reveal that nearly $15 \%-20 \%$ injury deaths occur in children (Zaidi et al., 2013).

Childhood injury is a leading global public health problem. It gives rise to loss of years of life and productivity, high financial burden to health care system, high household level out of pocket expenditure, substantial psychological impact on the child and family members and many other adverse consequences (Shriyan et al., 2014). In low and middle income countries (LMICs), young children face different types of household level hazards due to challenging living conditions such as poor housing infrastructure, unsafe storage places for harmful substances, lack of barriers to cooking and washing areas, use of open fires and stoves (Hyder et al., 2008a, b), thus making the child vulnerable to unintentional injury. This is even more important for the under-five children who spend major span of the day at home and cannot judge the potential risk owing to their immaturity (Hyder et al., 2009).

Many household level injury risks are avoidable requiring environmental modification which can be done with minimal efforts, suited to the affordability and feasibility for the family. However, there is a dearth of research work with comprehensive household level injury hazard identification for children in lower-income settings like rural India. With this background, this study was conducted to measure the burden of household level injury of 1 to 5 -year-old children in a rural area of Singur, West Bengal, India, to identify major risk situations in or around home leading to injury proneness, and to determine precipitating factors, if any, among the study participants. 


\section{Materials and Methods}

\section{Study Setting}

A community based cross-sectional study was conducted for a period of 4 months (November 2015 to February 2016) in the rural area of Singur block, situated in Hooghly district of West Bengal, India. The area covers 1,06,000 population served through two Primary Health Centres, four Subcentres and 12 Health Units. Children between 12-59 months of age were included in the study, as they have extensive exposure to the home environment and it was hypothesized that their injury profile should have a relationship with household level injury risks. Children less than 12 months of age were purposively excluded since average age of initiation of crawling is 9 months, before which the movement of child usually remains restricted; hence household level injury risk may not be associated with their injury profile.

\section{Sampling design and sample Size}

Considering the prevalence of unintentional injury as $46.3 \%$ (obtained from a previous study conducted at rural Karnataka) (Zaidi et al., 2013); using 5\% alpha error, allowable error 10\% and design effect 1.5, the sample size obtained was 148 and another $10 \%$ was added to make up for the non-response rate. Therefore, the minimum sample size was 163 . Children between 12-59 months of age, residing in that house for last 3 months, and whose parents gave informed consent were included in the study. Children who had a physical and sensory disability or a significant developmental delay that would make them more prone to injuries, were excluded from the study. Injuries that occurred because of interpersonal violence and self-harm or occurring outside home premises were not included in the study.

The area is served by 12 health units, two of them were chosen randomly, and two villages were chosen randomly from each unit. List of the households with children of 12-59 months' age group was obtained from the registers of the units. Number of sample households taken from each village was calculated using Probability Proportional to Size Method. From each village, the households were selected using simple random sampling. If there was more than one child of 1259 months' age group in one household, one was selected randomly.

\section{Study tool and technique}

Primary caregiver was interviewed using a pretested, interviewer administered questionnaire in Bengali language and a pretested household level injury hazard assessment checklist was also filled up by the researcher. A child was considered to have an injury episode when it was serious enough to meet any of the following criteria: injury requiring any type of medical care or cessation of regular activity, such as playing, for at least one day as a sequel of sustaining injury.

Parental supervisory behaviour was assessed using a pretested questionnaire in local (Bengali) language, adapted from Parent Supervision Attributes Profile Questionnaire (PSAPQ) (Morrongiello et al., 2006) and prepared based on its four domains - protectiveness, supervision beliefs, risk tolerance, and fate influences on child safety. Responses were recorded in a 5 point Likert scale, where increasing score indicates unfavourable behaviour (Cronbach's alpha-0.67$0.72)$.

Household level injury hazard was assessed using a pretested checklist. It was developed based on the review of existing tools, expert consultation with health care providers of emergency department of local health facility and experts from the department of Preventive and Social medicine, All India Institute of Hygiene and Public Health, Kolkata This tool was translated into the local language (Bengali) and pretested in 20 households in the adjacent village to test for ease of use, relevance, and understanding. It was revised based on the responses obtained in pre-testing and finalized for use in this study.

Sample households were chosen using random number table. In the event of non-response due to any reason from the selected household or if the door was found to be locked even after 3 
consecutive visits, another household was selected by simple random sampling. Interview of the primary caregiver of the child was done after obtaining informed consent and assuring anonymity and confidentiality. With the permission of the family members, the interviewer noted presence/absence of each home injury hazard on the checklist at the end of data collection; caregivers were advised regarding injury prevention measures by minor household modifications.

\section{Data analysis}

Household level injury hazards were scored (1 mark for presence of each hazard) for each household. Hazard score was calculated by adding up the hazards present in that household using the checklist and it was kept as continuous variable during analysis. As the checklist had 25 items, maximum and minimum attainable score were 25 and 0 , respectively; increasing score indicated increasing hazard/risk. Parental supervisory behaviour- depending upon the response in 5 point Likert scale, each parental behaviour was scored from 1 to 5 , where increasing score indicated unfavourable behaviour. Total score was calculated by adding scores of all the questions. Responses were categorized as unfavourable and favourable, considering median score as cut-off. Multivariable binary logistic regression model was generated using SPSS software, version 19.0 (Statistical Package for the Social Sciences Inc, Chicago, IL, USA), where the dependent variable was presence of unintentional injury. The independent variables with p-value less than 0.1 in bivariate logistic regression analysis were entered into a multivariable logistic model by "Forced Entry" method. P-value less than 0.05 was considered as statistically significant.

\section{Results}

A total of 163 children were involved in the study. The mean age of the study participants was 39.74 months. Children of both sexes were almost equally distributed in the study (female $57.7 \%)$. Majority of the children were Hindus (77.9\%) the rest $(22.1 \%)$ were Muslims. Mothers were the primary caregiver in $89.6 \%$ of the children, and majority of them being homemakers $(83.4 \%)$. Seventeen (10.4\%) of the caregivers were grandmothers (Table 1). None of the parents had any type of physical disability. Majority of the child (103, 63.2\%) were residing in joint family. Among the total 163 children, 103 (63.2\%) were the only under-five member of their family, and the rest $36.8 \%$ had brother/sister at under-five age group residing in the family.

Table 1: Background characteristics of the study subjects $(n=163)$

\begin{tabular}{|c|c|c|}
\hline \multirow{2}{*}{\multicolumn{2}{|c|}{$\begin{array}{l}\text { Variables } \\
\text { Age of the child (in completed months) }\end{array}$}} & Findings \\
\hline & & \\
\hline \multicolumn{2}{|c|}{ Mean[ $[ \pm S D]$} & $39.74[16.4]$ \\
\hline \multirow[t]{2}{*}{ Sex } & Male & $69(42.3)$ \\
\hline & Female & $94(57.7)$ \\
\hline \multicolumn{3}{|c|}{ Age of the primary caregiver (in completed years) } \\
\hline Median [IQR] & & $26[6]$ \\
\hline \multirow[t]{3}{*}{ Mother's occupation } & Homemaker & $136(83.4)$ \\
\hline & Bidi worker & $17(10.5)$ \\
\hline & Jewellery worker & $10(6.1)$ \\
\hline \multirow[t]{4}{*}{ Father's occupation } & Manual labour & $45(27.6)$ \\
\hline & Famer & $25(15 \cdot 3)$ \\
\hline & Businessman & $25(15 \cdot 3)$ \\
\hline & Service & $22(13.5)$ \\
\hline
\end{tabular}




$\begin{array}{ll}\text { Goldsmith } & 16(9.8) \\ \text { Driver } & 11(6.8) \\ \text { Mason } & 6(3.7) \\ \text { Others } & 13(8)\end{array}$

Father's year of schooling

Median [IQR]

Mother's year of schooling

Median [IQR]

Per capita income (in Indian Rupees)

Median [IQR]

Socio-economic status Class-I

$8(4.9)$

(according to modified B G Class II

Prasad's classification 2014)

Class III

$51(31.3)$

Number (\%)

Total family members

Median [IQR]

(Standard deviation (SD) and inter-quartile range (IQR) are expressed within third bracket [])

Out of total 163 children,61(37.4\%) underwent any type of injury and among them 10 had two episodes of injury during last 3 months' time period (Table 2).

Table 2: Description of injury events of the study subjects $(n=71)$

\begin{tabular}{llll}
\hline Variable & Response & Number & Percentage \\
\hline Mechanism of injury & Fall & 39 & 54.9 \\
& Fall of heavy object on the body & 11 & 15.5 \\
& Sharp injury & 7 & 9.9 \\
& Burn & 6 & 8.5 \\
& Pet bite & 5 & 7.0 \\
& Crush injury & 3 & 4.2 \\
\hline Place of occurrence of injury & Courtyard & 31 & 43.7 \\
& Bedroom & 28 & 39.4 \\
& Kitchen & 4 & 5.6 \\
& Stairs & 3 & 4.2 \\
& Bathroom & 3 & 4.2 \\
& Roof top & 2 & 2.8 \\
\hline Predominant body part involved & Upper limb & 16 & 22.5 \\
& Head & 13 & 18.3 \\
& Lower limb & 10 & 14.1 \\
& Back & 10 & 14.1 \\
& Forehead & 6 & 8.4 \\
Presence & Face & 5 & 7.1 \\
& Eye & 3 & 4.2 \\
& Ear & 2 & 2.8 \\
& Shoulder & 2 & 2.8 \\
& Others & 4 & 5.6 \\
\hline & Yes & 46 & 64.8 \\
& No & 25 & 35.2 \\
\hline
\end{tabular}




\begin{tabular}{llll}
\hline Outcome of injury & No treatment required/home & 38 & \\
& remedy & & 53.5 \\
& Managed at health facility OPD & 31 & 43.7 \\
& Hospitalization required & 2 & 2.8 \\
\hline
\end{tabular}

Tablez provides information on prevalence of individual home injury hazard. Majority of the children were exposed to sharp injury related hazards ( $97.5 \%)$, followed by injury due to fall of heavy objects (89.6\%), fall (74.2\%) and burn related hazards (57.1\%). Hazards in relation to choking (19.1\%), chemical (25.8\%), electricity (32.5\%) and drowning (41\%) were comparatively less (Table 2 ). Two thirds of the $71(64.8 \%)$ of the children sustained injury in the presence of care-givers. Majority (53.5) of the injured children did not require treatment or received home remedy; $43.7 \%$ were managed as out-patients at health facilities. Two children were hospitalised.

Table 3: Prevalence of home injury hazards for childhood unintentional injuries $(\mathrm{N}=163)$

\begin{tabular}{lll}
\hline $\begin{array}{l}\text { Type } \\
\text { injury }\end{array}$ & Home injury hazards & Number (\%) \\
\hline Fall related & Presence of any depression/uneven surface around the house & $25(15.3)$ \\
& Stair without railing (n=85) & $20(23.5)$ \\
& Accessible rooftop without a protective barrier (n=85) & $38(44.7)$ \\
& Courtyard which is at lower level & $108(66.3)$ \\
\hline Heavy & Bicycle that may fall on the child & $94(57.7)$ \\
object & Large unstable sack that may fall on the child & $77(47.2)$ \\
& Unstable furniture & $95(58.3)$ \\
\hline Sharp Injury & Knives or sharp objects used in kitchen & $108(66.3)$ \\
Related & Spade within child's reach & $43(26.4)$ \\
& Bed/furniture with sharp corners & $46(28.3)$ \\
& Pedestal fan within child's reach & $38(23.3)$ \\
& Glass materials (cup, mirror etc.) within child's reach & $52(31.9)$ \\
& Sharp stick within the reach of the child & $138(84.7)$ \\
\hline Burn related & Matches/lighter within reach of the child & $47(28.8))$ \\
& Open fire/Fireplace /Stove within reach of the child & $87(53.4)$ \\
\hline Electrocutio & Plug point/ switch board within the reach of the child & $36(22.1)$ \\
n Related & Open wire within the reach of the child & $23(14.1)$ \\
\hline Chemical & Phenyl/ acid used in bathroom within the reach of the child & $30(18.4)$ \\
& Medicine within the reach of the child & $10(6.1)$ \\
\hline Pet & Insecticides within the reach of the child & - \\
\hline Choking & Coin within the reach of the house & $22(13.5)$ \\
& Cosmetics / safety pin/ Other small choking hazards within reach of the child & $13(8)$ \\
\hline & Uncovered well inside the house without proper protective railing & $8(4.9)$ \\
& Pond adjacent to the house where child is free to go without supervision & $59(36.2)$ \\
\hline & Pet (dog/cat) regularly visits that house & $41(25.2)$ \\
\hline
\end{tabular}

Injury was found to be significantly associated with the presence of overcrowding in the household and where mother was working outside. Multivariable logistic regression model was significant as evident from the omnibus Chi-square statistic $\left(\chi^{2}=62.45, p<0.01\right)$. This model was a good fit as evident from non-significant Hosmer-Lemeshow statistic $(p=0.055)$. All the independent variables explained $43.7 \%$ variance of dependent variable by using Nagelkerke $\mathrm{R}^{2}$. Overall, our model correctly predicted $81 \%$ of outcomes, as shown by the classification table. Household level injury hazard and parental supervisory behaviour were found to be significantly associated with injury occurrence even when adjusted with other variables (Table 4). 
Table 4: Bivariate and multivariable logistic regression for predictors of unintentional injury $(n=163)$

\begin{tabular}{llllll}
\hline Co-variates & & $\begin{array}{l}\text { Total } \\
\text { children }\end{array}$ & $\begin{array}{l}\text { Injury present } \\
\text { number }(\%)\end{array}$ & OR $(\mathrm{Cl})$ & AOR $(\mathrm{Cl})$ \\
\hline Overcrowding & No & 103 & $32(31.1)$ & 1 & 1 \\
& Yes & 60 & $29(48.3)$ & $2.1(1.0-4.0)^{*}$ & $0.85(0.36-2.0)$ \\
Mother's & Homemaker & 136 & $46(33.8)$ & 1 & 1 \\
occupation & Working outside & 27 & $15(55.6)$ & $2.4(1.1-5.6)^{*}$ & $2.68(0.95-7.49)$ \\
$\begin{array}{l}\text { Primary } \\
\text { Caregiver }\end{array}$ & Mother & 146 & $51(34.9)$ & 1 & 1 \\
$\begin{array}{l}\text { Parental } \\
\text { Supervisory }\end{array}$ & Favourable & 57 & $14(26.4)$ & 1 & $3.04(0.93-9.98)$ \\
behaviour & Unfavourable & 106 & $47(44.3 \%)$ & $2.45(1.2-4.9)^{*}$ & $2.68(1.12-6.38) *$ \\
& & & & $1.5(1.3-1.7) *$ & $1.55(1.3-1.8) *$ \\
\hline
\end{tabular}

*Statistical significance $p<0.05$

\section{Discussion}

In this study, the incidence of unintentional injury using 3-month recall among the studied children was found to be $37.4 \%$. Parental supervisory behaviour and household level injury hazard score were found to be significantly predicting unintentional injury. Incidence of childhood unintentional injury elsewhere in India is much higher among under-five children (Alamgir et al., 2012; Shriyan et al., 2014; Chaudhari et al., 2008). However, the prevalence in this study is much less than in a study done at a slum of Karachi and a rural area of Pondicherry in India (Mahalakshmy et al., 2011; Khan et al., 2013). As a result of wide variation in socioeconomic status of different study populations and the likely variations in risk exposure, it is difficult to make meaningful comparisons between different studies. Moreover, working definitions of severity criteria for injury and inclusion criteria also varied from study to study.

The commonest cause of the injuries was due to falls followed by fall of a heavy object on the body, sharp injury and burn. This result conforms to few previous studies (Zaidi et al., 2013, Shriyan et al., 2014, Pant et al., 2015). In this study boys were found to be suffering from injury more than girls. This finding was similar to a study conducted by Eldosoky et al. (2012) and Pant et al. (2015) where the boys had sustained more injuries. This study revealed that the commonest site of injury was upper limb, followed by head and lower limb. Contrary to the findings of this study, Shriyan et al. (2014) found that half of the injuries had occurred in the lower extremity. Zaidi et al. (2013) in their study revealed that injuries in the lower extremity and head, face and neck were equally distributed.

Santo et al. (2004) observed that childhood injury is a complex phenomenon predicted by both endogenous (cognitive and behavioural) as well as exogenous determinants (socio-demographic and housing variables). They also found an interaction of maternal perceptions of risk variables with maternal safety behaviour variables while predicting injury risk in a Cox regression model. Another follow-up study by Morrongiello et al. (2004) has shown that both child (i.e. risk taking) and parent (i.e. protectiveness) factors were significant determinants of childhood injury. Moderating effect of supervision with other attributes in relation to increasing injury risk was reported in a different study on 2-5 years children (Morrongiello et al. 2008). In this study, parental supervisory behaviour as well as household level injury hazard score were found to be significantly predicting unintentional injury, and even when adjusted with other variables, they remained significant.

Risks for falls, drowning, burns and poisoning identified in this study are similar to the ones reported from families with young children in other Low and Medium Income Countries (Jordan et al., 2005, Chaudhari et al.,2008; Khan et al., 2013). Chaudhari et al. (2008) reported a shocking observation that an overwhelming majority of boys and girls in the urban slum areas of Surat, and Gujarat were exposed to fire hazards as it was within reach in their homes and surprisingly 
perceived to be safe by the parents. Our study reported much lower percentage of children exposed to any type of fire hazard. Three fifth boys were found to be at risk of injury to household chemicals kept within reach in an urban slum area of Gujarat (Chaudhari et al., 2008) as compared to about a quarter of the children with the similar risk in this study, which highlights more hazardous nature of domestic environment in that urban slum as compared to our study setting. One-third of the children were found to be at risk of electric appliances within reach in their houses as compared to less than a quarter in an urban slum area of Gujarat (Chaudhari et al., 2008). In our study, an accessible rooftop lacked a protective barrier in a substantial proportion of the households, the result being in line with that reported from an urban slum of Pakistan (Khan et al., 2013). Stove within the reach of the child was also comparable with the findings of a study done at coastal Karnataka, India (Khan et al., 2013). The association between lower levels of parental education with risk of injury in a child is well established (Gielen et al., 2002), but this association was not found in this study.

This study has some limitations like cognitive function of the parents and child's risk-taking behaviour; the well-known predictors of unintentional injury (Howe et al., 2006) were not evaluated in the study. Only one child was selected from each household, which might have introduced selection bias. As 3 months' recall of injury was obtained, possibility of recall bias cannot be ruled out. However, the main strength of this study was that a household level injury hazards checklist was developed after pretesting, and discussion with specialists, considering the local context, and using that checklist, exact housing conditions and household level injury hazards were observed by the investigator. This type of checklist has not been developed previously for rural West Bengal setting, the advantage being locally relevant household modifiable factors can be identified easily.

In conclusion, in high income countries, the prevention of home injuries has been attempted through counselling and education by home visits and provision of safety equipment. Unfortunately, the dissemination of injury prevention information is neglected in India. Based on the findings of this study, it can be strongly recommended that home visits related to identification of injury risks and health education by the grass root level health care providers need to be considered as essential strategies for preventing unintentional injury in this country. Parents must also be counselled regarding economically feasible modifications in the household that can prevent deadly injury in their off-springs.

\section{References}

Alamgir, M., Mahboob, S., Ahmed, K., Islam, M., Gazi, S., \& Ahmed, A. (2012) Pattern of Injuries Among Children of Urban Slum Dwellers in Dhaka City. Journal of Dhaka National Medical College \& Hospital18, 24-28.

Chaturvedi, S. (2008) Injury: the most underappreciated and unattended pandemic. Indian Journal of Public Health52, $115-116$.

Chaudhari, V., Srivastava, R., Moitra, M. \& Desai, V. (2008) Risk of domestic accidents among under five children. The Internet Journal of Family Practice7 (1):1-7.

Dal, Santo., J.A., Goodman, R.M., Glik, D. \& Jackson, K. (2004) Childhood unintentional injuries: factors predicting injury risk among pre-schoolers. Journal of Pediatric Psychology29, 273283.

Eldosoky, R.S.H. (2012) Home-related injuries among children: knowledge, attitudes and practice about first aid among rural mothers. Eastern Mediterranean Health Journal18, 1021.

Forjuoh, S.N. (2006) Burns in low and middle income countries: a review of available literature on descriptive epidemiology, risk factors, treatment, and prevention. Burns 32, 529-537.

Gielen, A.C., McDonald, E.M., Wilson, M.E.H., Hwang, W-T., Serwint, J.R., Andrews, J.S. \& Wang, M.C. (2002) Effects of improved access to safety counseling, products, and home visits on 
parents' safety practices: results of a randomized trial. Achieves of Pediatrics and Adolescent Medicine 156, 33-40.

Howe, L.D., Huttly, S.R. \& Amramsky, T., (2006) Risk factors for injuries in young children in four developing countries: the young lives study. Tropical Medicine and International Health 11, 1557-1566

Hyder, A.A., Wali, S., Fishman, S. \& Schenk, E. (2008) The burden of unintentional injuries among the underfive population in South Asia. Acta Paediatrica97, 267-275.

Hyder, A.A., Borse, N.N., Blum, L., Khan, R., El, Arifeen, S.\& Baqui, A.H. (2008) Childhood drowning in low and middle income countries: urgent need for intervention trials. Journal of Paediatrics and Child Health44, 221-227.

Hyder, A.A., Sugerman, D.E., Puvanachandra, P., Razzak, J., El-Sayed, H., Isaza, A., Rahman, F. \& Peden, M. (2009) Global childhood unintentional injury surveillance in four cities in developing countries: a pilot study. Bulletin of the World Health Organization87, 345-352.

Jordaan, E.R., Atkins, S., van, Niekerk, A.\& Seedat, M. (2005) The development of an instrument measuring unintentional injuries in young children in low income settings to serve as an evaluation tool for a childhood home injury prevention program. Journal of Safety Research 36, 269-280.

Khan, U.R., Chandran, A., Zia, N., Huang, C.M., Stewart De Ramirez, S., Feroze, A., Hyder, A.A., Razzak, J.A. (2013) Home injury risks to young children in Karachi, Pakistan: a pilot study. Archives of Disease in Childhood 98, 881-886.

Mahalakshmy, T., Dongre, A.R. \& Kalaiselvan, G. (2011) Epidemiology of childhood injuries in rural Puducherry, South India. Indian Journal of Pediatrics 78, 821-825.

Morrongiello, B. A., Ondejko, L. \& Littlejohn, A. (2004) Understanding Toddlers' in-Home Injuries: I. Context, Correlates, and Determinants. Journal of Pediatric Psychology 29, 415-431.

Morrongiello, B.A.\& Corbett, M. (2006) The parent supervision attributes profile questionnaire: a measure of supervision relevant to children's risk of unintentional injury. Injury Prevention $12,19-23$.

Morrongiello, B.A. Klemencic, N. \& Corbett, M. (2008) Interactions Between Child Behavior Patterns and Parent Supervision: Implications for Children's Risk of Unintentional Injury. Child Development 79, 627-38

Pant, P.R., Towner, E., Ellis, M., Manandhar, D., Pilkington, P. \& Mytton, J. (2015) Epidemiology of Unintentional Child Injuries in the Makwanpur District of Nepal: A Household Survey. International Journal of Environmental Research and Public Health 12, 15118-15128

Shriyan, P., Prabhu, V., Aithal, K.S., Yadav, U.N.\& Orgochukwu, M.J. (2014) Profile of unintentional injury among under-five children in coastal Karnataka, India: a cross-sectional study. International Journal of Medical Sciences and Public Health 3, 1317-1319.

WHO (2008) Violence and Injury Prevention, Child injuries. World Health Organization, http://www.who.int/violence injury_prevention/child/injury/en/. Accessed:28.7.2016

Zaidi, S.H.N., Khan, Z., Khalique, N. (2013) Injury pattern in children: a population based study. Indian Journal of Community Health 25:45-51. 